\title{
The Importance of 11a-OH, 15-oxo, and 16-en Moieties of 11a-Hydroxy-15-oxo-kaur-16-en-19-oic Acid in Its Inhibitory Activity on Melanogenesis
}

\author{
Azusa Kuroi ${ }^{a, b}$ Koji Sugimurac, d Ayako Kumagaia, e Arihiro Koharaf

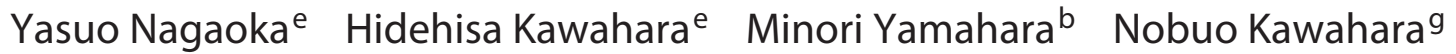 \\ Hiroshi Takemoria, h Hiroyuki Fuchino ${ }^{g}$ \\ ${ }^{a}$ Cell Signaling and Metabolic Disease, National Institutes of Biomedical Innovation, Health and Nutrition, Ibaraki, \\ ${ }^{b}$ Department of Research and Development, Momotani Juntenkan Ltd., Osaka, ${ }^{\mathrm{C}}$ Research Center for Medicinal Plant \\ Resources, Tanegashima Division, National Institutes of Biomedical Innovation, Health and Nutrition, Kumage-gun, \\ ${ }^{\mathrm{d}}$ Department of Medical Plant, School of Pharmacy, Kumamoto University, Kumamoto, e Department of Life Science \\ and Biotechnology, Faculty of Chemistry, Materials and Bioengineering, Kansai University, Suita, ${ }^{f} J a p a n e s e ~ C o l l e c t i o n$ \\ of Research Bioresources Cell Bank (JCRB), National Institutes of Biomedical Innovation, Health and Nutrition, Ibaraki, \\ ${ }^{9}$ Research Center for Medicinal Plant Resources, Tukuba Division, National Institutes of Biomedical Innovation, \\ Health and Nutrition, Tsukuba, and h Department of Chemistry and Biomolecular Science, Faculty of Engineering, \\ Gifu University, Gifu, Japan
}

\section{Keywords}

Melanogenesis · Microphthalmia-associated transcription factor · Tyrosinase · Pteris dispar Kunze

\begin{abstract}
Cosmetic industries have an interest in exploring and developing materials that have the potential to regulate melanin synthesis in human skin. Although melanin protects the skin from ultraviolet irradiation, excess melanin can be undesirable, particularly on the face where spots or freckles are associated with an appearance of aging. In this study, we found that ent-11a-hydroxy-15-oxo-kaur-16-en-19-oic acid (11a-OH KA) in Pteris dispar Kunze strongly inhibited melanin synthesis by suppressing tyrosinase gene expression. The melanogenic transcription factor microphthalmia-associated transcription factor (MITF) is required for this suppression. However, 11a$\mathrm{OH} \mathrm{KA}$ did not modulate the expression level or activity of MITF. Structure-activity relationship analyses suggested that the $11 \mathrm{a}-\mathrm{OH}, 15-\mathrm{OxO}$, and 16-en moieties of $11 \mathrm{a}-\mathrm{OH} \mathrm{KA}$ are essential for the suppression of melanin synthesis. On the other
\end{abstract}

\section{KARGER}

(C) 2017 S. Karger AG, Basel

E-Mail karger@karger.com

www.karger.com/spp hand, the 19-COOH moiety is important for preventing cellular toxicity associated with $11 \mathrm{a}-\mathrm{OH} \mathrm{KA}$ and its related compounds. These results suggest that $11 \mathrm{a}-\mathrm{OH} \mathrm{KA}$ is an attractive target for potential use in the production of cosmetic items.

(c) 2017 S. Karger AG, Basel

\section{Introduction}

Melanin plays a crucial role in protecting the skin from ultraviolet (UV) components of sunlight. In addition, melanin neutralizes free radicals and scavenges toxic drugs and chemicals [1]. However, generation of excess melanin causes visible hyperpigmentation of the epidermis, resulting in freckles, melasma, and age spots [2].

Hyperpigmentation results from an increased number or activity of melanocytes [3]. Melanin synthesis is regulated by tyrosinase (EC 1.14.18.1), which catalyzes hy-

Azusa Kuroi, MS

Department of Research and Development, Momotani Juntenkan Ltd.

1-4-1, Uemachi

Osaka 540-0005 (Japan)

E-Mail a-kuroi@e-cosmetics.co.jp

Hiroshi Takemori, PhD

Department of Chemistry and Biomolecular Science, Faculty of Engineering Gifu University, Yanagido 1-1

Gifu 501-1193 (Japan)

E-Mail htake@gifu-u.ac.jp 
droxylation of L-tyrosine to 3,4-dihydroxyphenylalanine and its subsequent oxidation to dopaquinone. Dopaquinone is converted to melanin via enzymatic and nonenzymatic reactions [4]. To achieve skin whitening, control of tyrosinase activity and its expression level is important. A number of substances, including linoleic acid [5], hinokitiol [6], kojic acid [7], hydroquinone [8], catechols [9], and salicylate [10], are widely used in cosmetic items where they act as tyrosinase inhibitors.

The regulation of tyrosinase expression levels in melanocytes is a multistep process. First, UV radiation stimulates keratinocytes to synthesize and secrete $\alpha$-melanocyte-stimulating hormone ( $\alpha-\mathrm{MSH})$ [11]. $\alpha$-MSH then binds to the melanocortin 1 receptor on the melanocyte membrane, which initiates cAMP signaling in the melanocytes. CAMP signaling activates the transcription factor cAMP response element-binding protein (CREB), which induces the melanogenic transcription factor microphthalmia-associated transcription factor (MITF) $[12,13]$. In turn, MITF binds to the tyrosinase promoter and upregulates the expression of this gene. We have recently identified carnosol and canosic acid from Callicarpa longissima as candidates for skin whitening reagents that act by targeting MITF expression [14].

Here, we report that ent-11a-hydroxy-15-oxo-kaur16-en-19-oic acid (11a-OH KA), an ingredient in the Pteris dispar Kunze leaf extract strongly inhibited melanin synthesis in B16F10 melanoma cells and in a threedimensional (3D) human skin epidermal model. Although $11 \alpha-\mathrm{OH}$ KA did not alter the expression level or activity of MITF in cAMP-agonist (forskolin, Fsk)-treated cells, it significantly suppressed tyrosinase expression levels. Structure-activity relationship analyses revealed that the 11a-OH, 15-oxy, and 16-en moieties were essential for melanogenesis inhibitory activity of $11 \alpha-\mathrm{OH}$ KA.

\section{Materials and Methods}

\section{Chemicals}

Authentic 11a-OH KA and related kaurens were obtained from BioBioPha (Shanghai, China). Antibodies were obtained as follows: anti-tyrosinase (Santa Cruz Biotechnology, Inc., Santa Cruz, CA, USA), anti-MITF (Thermo Fisher Scientific Inc., Waltham, MA, USA), anti-GAPDH (WAKO, Kyoto, Japan), anti-CREB (Genscript, Piscataway, NJ, USA), and p38, pp38, ERK1/2, pERK1/2, and pCREB (Cell Signaling Technology, Danvers, MA, USA). Antigen-antibody interactions were visualized using Chemi Doc XRS (Bio-Rad, Hercules, CA, USA) with the Chemi-Lumi One Super reagent (Nacalai Co. Ltd., Kyoto, Japan) or using the chromogenic reagent immunostain horseradish peroxidase (ATTO Co., Ltd., Tokyo, Japan).
Purification and Analysis of $11 \alpha-O H K A$

Fifty grams of dried powder made from the leaves of $P$. dispar Kunze was soaked in $500 \mathrm{~mL}$ of methanol, and the resulting extract was passed through $50 \mathrm{~g}$ of activated charcoal and was then concentrated to approximately $10 \mathrm{~mL}$ (forming viscous precipitates) by evaporation. Viscous precipitates were first washed with $10 \mathrm{~mL}$ chloroform and were then re-resolved with $10 \mathrm{~mL}$ of methanol to which $500 \mathrm{~mL}$ chloroform was added. After removal of unresolved materials by filtration, solvents were re-evaporated. Substances were then concentrated to approximately $20 \mathrm{~mL}$ and were applied onto a silica gel column (100 mL; Nacalai, Kyoto, Japan). Melanin-suppressing substances were eluted as 2 peaks when chloroform:methanol (85:15) was used as the eluate. The latter peak fraction was concentrated and applied onto a $\mathrm{C}_{18}$-ODS column $(4.6 \times 50 \mathrm{~mm}$, Cosmosil MS-II; Nacalai). The main peak was collected, and substances were recovered in ethyl acetate and reconcentrated by evaporation. The precipitates were then dissolved in $1 \mathrm{~mL}$ of ethanol to be hydrolyzed with $9 \mathrm{~mL}$ of $1 \% \mathrm{H}_{2} \mathrm{SO}_{4}$-water at $100^{\circ} \mathrm{C}$ for $30 \mathrm{~min}$. The hydrolyzate was recovered in ethyl acetate, evaporated, suspended in $20 \%$ acetonitrile-water, and applied again onto the $\mathrm{C}_{18}$-ODS column. The main peak was collected, and substances were again recovered in ethyl acetate and re-concentrated by evaporation.

Fr. 6 and $6^{\prime}$ (hydrolyzed) were purified by recycling HPLC onto an ODS column $(15 \times 150 \mathrm{~mm}$ i.d., SunFire Prep C18 OBD, Waters; solvent system, $20 \%$ acetonitrile/water) to obtain $11 a-O H ~ K A$ (2.0 mg).

\section{Preparation of $11 \alpha-O H$ KA Methyl Ester}

Synthesis of $11 \alpha-O H$ KA methyl ester was prepared as described previously [15]. Briefly, 11a-OH KA (5 mg, $\left.1.6 \times 10^{-5} \mathrm{~mol}\right)$ was reacted with $\mathrm{CH}_{3} \mathrm{I}\left(4.1 \mu \mathrm{L}, 7.5 \times 10^{-5} \mathrm{~mol}\right)$ and $\mathrm{K}_{2} \mathrm{CO}_{3}(10 \mathrm{mg}$, $\left.6.5 \times 10^{-5} \mathrm{~mol}\right)$ in $\mathrm{N}, \mathrm{N}$-dimethylformamide $(200 \mu \mathrm{L})$. After being

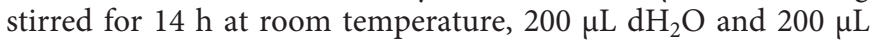
ethyl acetate were added, and $11 \alpha-\mathrm{OH}$ KA methyl ester was recovered in the ethyl acetate phase. After removal of ethyl acetate by evaporation, 11a-OH KA methyl ester was directly confirmed by LC/MS and NMR.

\section{$N M R$}

11a-OH KA: colorless amorphous powder; ${ }^{1} \mathrm{H}-\mathrm{NMR}\left(\mathrm{CDCl}_{3}+\right.$ $\left.\mathrm{CD}_{3} \mathrm{OD}, 600 \mathrm{MHz}\right) \delta: 0.85(3 \mathrm{H}, \mathrm{s}), 1.14(3 \mathrm{H}, \mathrm{s}), 2.29(1 \mathrm{H}, \mathrm{d}, J=12.0$ $\mathrm{Hz}), 2.95(1 \mathrm{H}$, broad s), $3.93(1 \mathrm{H}, \mathrm{d}, J=4.6 \mathrm{~Hz}), 5.16(1 \mathrm{H}, \mathrm{s}), 5.73$ $(1 \mathrm{H}, \mathrm{s}) ;{ }^{13} \mathrm{C}-\mathrm{NMR}\left(\mathrm{CDCl}_{3}+\mathrm{CD}_{3} \mathrm{OD}, 600 \mathrm{MHz}\right) \delta: 40.5(\mathrm{C}-1), 18.7$ (C-2), 37.8 (C-3), 43.4 (C-4), 55.8 (C-5), 19.8 (C-6), 33.7 (C-7), 50.6 (C-8), 62.8 (C-9), 38.8 (C-10), 65.7 (C-11), 65.7 (C-12), 36.8 (C13), 36.4 (C-14), 210.7 (C-15), 150.3 (C-16), 112.7 (C-17), 28.8 (C18), 180.4 (C-19), 15.4 (C-20); HRESI-OrbitrapMS m/z 333.2066 (calcd for $\mathrm{C}_{20} \mathrm{H}_{29} \mathrm{O}_{4}, 333.2060$ ).

11a-OH KA methyl ester: colorless amorphous powder; ${ }^{1} \mathrm{H}$ $\operatorname{NMR}\left(\mathrm{CDCl}_{3}, 600 \mathrm{MHz}\right) \delta: 0.76(3 \mathrm{H}, \mathrm{s}), 1.14(3 \mathrm{H}, \mathrm{s}), 2.28(1 \mathrm{H}, \mathrm{d}$, $J=11.9 \mathrm{~Hz}), 2.99\left(1 \mathrm{H}\right.$, broad s), $3.58\left(3 \mathrm{H}, \mathrm{s}, \mathrm{CH}_{3} \mathrm{OCO}-\right), 3.98(1 \mathrm{H}$, $\mathrm{d}, J=4.6 \mathrm{~Hz}), 5.20(1 \mathrm{H}, \mathrm{s}), 5.81(1 \mathrm{H}, \mathrm{s}) ;{ }^{13} \mathrm{C}-\mathrm{NMR}\left(\mathrm{CDCl}_{3}, 600\right.$ $\mathrm{MHz})$ \&: 41.1 (C-1), 18.8 (C-2), 37.8 (C-3), 43.8 (C-4), 56.0 (C-5), 20.0 (C-6), 33.8 (C-7), 50.6 (C-8), 63.2 (C-9), 38.8 (C-10), 66.3 (C11), 39.8 (C-12), 36.9 (C-13), 36.5 (C-14), 209.8 (C-15), 150.3 (C16), 113.0 (C-17), 28.8 (C-18), 177.8 (C-19), 15.4 (C-20), 51.4 $\left(\mathrm{OCH}_{3}\right)$; HRESI-OrbitrapMS $m / z 347.2224$ (calcd for $\mathrm{C}_{21} \mathrm{H}_{31} \mathrm{O}_{4}$, 347.2217). DOI: 10.1159/000475471
Kuroi et al. 


\section{Cell Culture}

Mouse B16F10 melanoma cells from the American Type Culture Collection (Manassas, VA, USA) were cultured in Dulbecco's modified Eagle's medium (DMEM, $5.5 \mathrm{mM}$ D-glucose; WAKO), supplemented with $10 \%$ fetal bovine serum and antibiotics. Cells were incubated in a humidified atmosphere with $5 \% \mathrm{CO}_{2}$ at $37^{\circ} \mathrm{C}$ and were transferred every 2 days via trypsinization to new culture dishes.

\section{Human Epidermal Equivalents (3D Human Skin Model)}

Preparation of materials from human souse was undertaken through the application and approval of strict ethical principles of the provider Japan Tissue Engineering Co., Ltd., Aichi, Japan (also see http://www.jpte.co.jp/english/business/ethical_policy.html). The human epidermal equivalents, consisting of multilayered human keratinocytes and melanocytes (LabCyte Melano-Model, Tissue Engineering Co., Ltd., Aichi, Japan), were cultured at $37^{\circ} \mathrm{C}$ in the manufacturer-supplemented melanogenic medium (with stem cell factor and endothelin 1). Compounds were dissolved in PBS and applied to the surface of the epidermis tissue. The media and compounds were exchanged every 2 days. After 14 days, epidermal equivalents were subjected to melanin measurement and visualization.

\section{Fontana-Masson Staining}

Cell layers of 3D human skin models were fixed in $4 \%$ paraformaldehyde/PBS for $24 \mathrm{~h}$ and embedded in paraffin. Melanin on sections ( $3 \mu \mathrm{m}$ thick) was visualized by Fontana-Masson staining.

\section{Assay for Melanin Content}

Melanin measurement was performed as described previously [14]. Briefly, the cells were washed twice with phosphate-buffered saline and were recovered in $2-\mathrm{mL}$ collection tubes, followed by centrifugation at $8,000 \mathrm{rpm}$ for $1.5 \mathrm{~min}$. Each cell pellet was suspended in $300 \mu \mathrm{L}$ of $1 \mathrm{M} \mathrm{NaOH}$ and were then lysed by incubation at $45^{\circ} \mathrm{C}$ for $2 \mathrm{~h}$. Melanin was extracted with a 2:1 chloroformmethanol mixture and was measured with a spectrophotometer (Model 680; Bio-Rad, Hercules, CA, USA) at $405 \mathrm{~nm}$. The protein concentration of the cell pellets was determined using Bradford reagent (Bio-Rad) and was used for normalization of the melanin content.

\section{Quantitative Real-Time PCR}

Quantitative real-time PCR analysis, including primer sets, has been described previously [14]. Briefly, total RNA was extracted using an EZ1 RNA Universal Tissue Kit (Qiagen, The Netherlands), and cDNA was synthesized using a ReverTra Ace qPCR RT Master Mix (Toyobo, Osaka, Japan). qPCR amplification was performed using EXPRESS SYBR GreenER (Thermo Fisher Scientific). Each of the mRNA expression levels were normalized against the GAPDH mRNA.

\section{Reporter Assay}

Procedures of recombinant DNA experiments were approved by the Committee in National Institutes of Biomedical Innovation, Health and Nutrition. The pGL3-mouse tyrosinase promoter and mouse MITF overexpression vectors have been described previously [14]. To prepare the $3 \times \mathrm{M}$-box-luciferase vector, 2 complementary nucleotides ( $5^{\prime}$-CGC GAA AAG TCA GTC ATG TGC TTT TCA AAA GTC AGT CAT GTG C TT TTC AAA AGT CAG

11a-Hydroxy-15-oxo-kaur-16-en-19-oic

Acid on Inhibition of Melanogenesis
TCA TGT GCT TTT C and 5'-GAT CGA AAA GCA CAT GAC TGA CTT TTG AAA AGC ACA TGA CTG ACT TTT GAA AAG CAC ATG ACT GAC TTT T) were annealed at room temperature. The DNA fragment was ligated into the $M l u$ I/ $B g l$ II site of the pTAL-luciferase vector (Takara, Kyoto, Japan).

To construct the mouse tyrosinase promoter with mutation, primers were used in which the M-box region TCA GTC ATG TG was converted to GCG GCC GCG TG using $5^{\prime}$ and $3^{\prime}$ 20-mer flanking regions. For E-box mutation, the E-box region CAT GTG was converted to GGA TCC. The pGL3-mouse tyrosinase promoter vector was amplified using these primers. To construct the double mutant, the M-box mutant vector was amplified using the E-box mutation primers.

Using Lipofectamine 2000 (Thermo Fisher Scientific, Carlsbad, CA, USA), B16F10 melanoma cells plated onto a 24-well plate were cotransfected with the pGL3-mouse tyrosinase promoter or pTAL $3 \times$ M-box $(0.25 \mu \mathrm{g} /$ well $)$ with the internal reporter pRL-TK $(0.05$ $\mu \mathrm{g})$, in the presence or absence of the Mitf expression vector (pTarget-mouse Mitf, $0.05 \mu \mathrm{g})$. After $24 \mathrm{~h}$, the Fsk $(20 \mu \mathrm{M})$ and $11 \alpha-\mathrm{OH}$ KA $(1-30 \mu \mathrm{M})$ were added, and cells were cultured further for $24 \mathrm{~h}$. Reporter activity was monitored using the Dual Luciferase Reporter Assay Kit (Promega).

\section{Results}

\section{Purification of Melanin-Synthesis Inhibitors from}

P. dispar

To identify plant extracts that contain unique melanogenesis suppressors, we collected the leaves of $>100$ ferns and assessed their ability to inhibit melanin synthesis in Fsk-stimulated B16F10 melanoma cells. Of all plants tested from the fern-library, the extract from $P$. dispar Kunze showed the strongest inhibitory effect on melanin synthesis.

To identify the active inhibiting components of the extract, we first soaked the leaves in methanol and passed the extract through an activated charcoal column. Then, we fractionated the eluent by silica gel chromatography (Fig. 1a) and separated the candidates into 2 fractions (fraction [Fr.] 4 and 6; Fig. 1b). LC-MS analyses suggested that Fr. 6 contained glycosylated compounds composed in Fr 4. Additionally, the main peak after LC separation $\left(\mathrm{C}_{18}\right.$-ODS) appears to be composed of at least 2 compounds with a difference of 2 atomic mass units. Because Fr. 4 contained fewer substances than Fr. 6, we tried to separate the main peak in Fr. 6 into the 2 component compounds by recycling column chromatography (Fig. 1c).

After 10 cycles, the 2 compounds were clearly separated, and a thin-layer chromatograph revealed that 1 compound showed strong absorption under UV irradiation (254 nm) (Fr. B) and the other did not (Fr. A) (Fig. 1d).

Skin Pharmacol Physiol 2017;30:205-215 
a

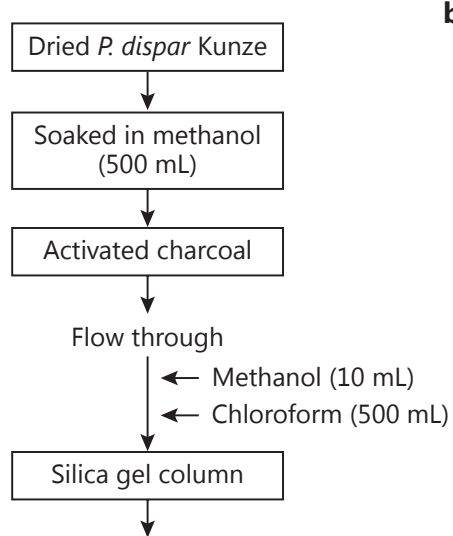

85:15 chloroform:methanol fraction (Fr. 6)

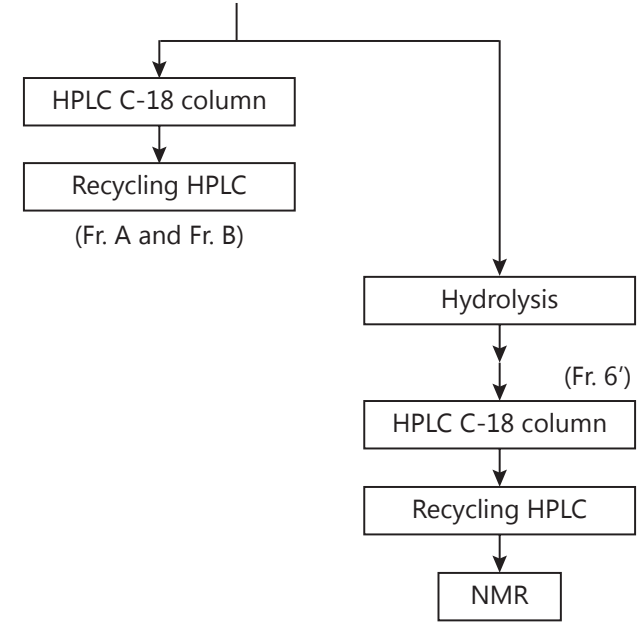

b $c^{x^{x}}+$ Fsk

\begin{tabular}{llllll|l|lllll} 
Fraction No. & 1 & 2 & 3 & 4 & 5 & 8 & 9 & 10 \\
& & & & & & & & & & &
\end{tabular}

C

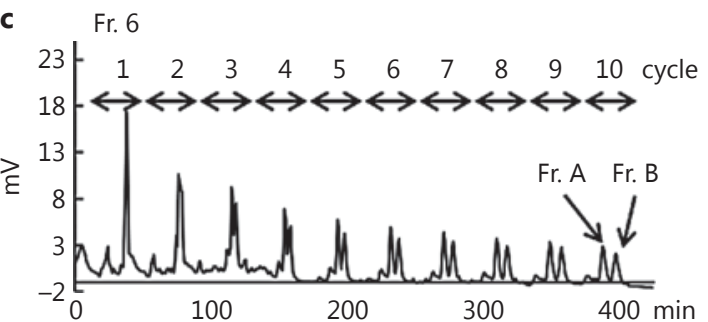

Fig. 1. Purification of melanin synthesis inhibitors from $P$. dispar. a A flow chart of the purification of melanin synthesis inhibitors. b Fractions after the silica gel chromatography were evaluated by melanin synthesis inhibition in B16F10 melanoma cells. The cells were incubated with $20 \mu \mathrm{M}$ forskolin (Fsk) in the presence of each fraction (1/10,000 dilution) for $48 \mathrm{~h}$ and were collected into $1.5-\mathrm{mL}$ tubes. Melanin contents were judged by visual evaluation. Fraction (Fr.) 6 was further separated using HPLC with a C18-ODS column. c The main peak in Fr. 6 was collected and applied onto a recycling
HPLC column. After 10 cycles, 2 ingredients were separated as 2 peaks (Fr. A and Fr. B). d The ingredients were separated by thinlayer chromatography and visualized by UV (245 nm) (upper image) or by $0.1 \%$ sulfuric acid (lower image). e Predicted structures of ingredients in Fr. A and Fr. B are indicated. Fr. B shows melanin synthesis-inhibitory activity in B16F10 cells. $f$ The main component in Fr. 6 could be hydrolyzed and converted into a hydrophobic product, which was confirmed by the C18-ODS column. 


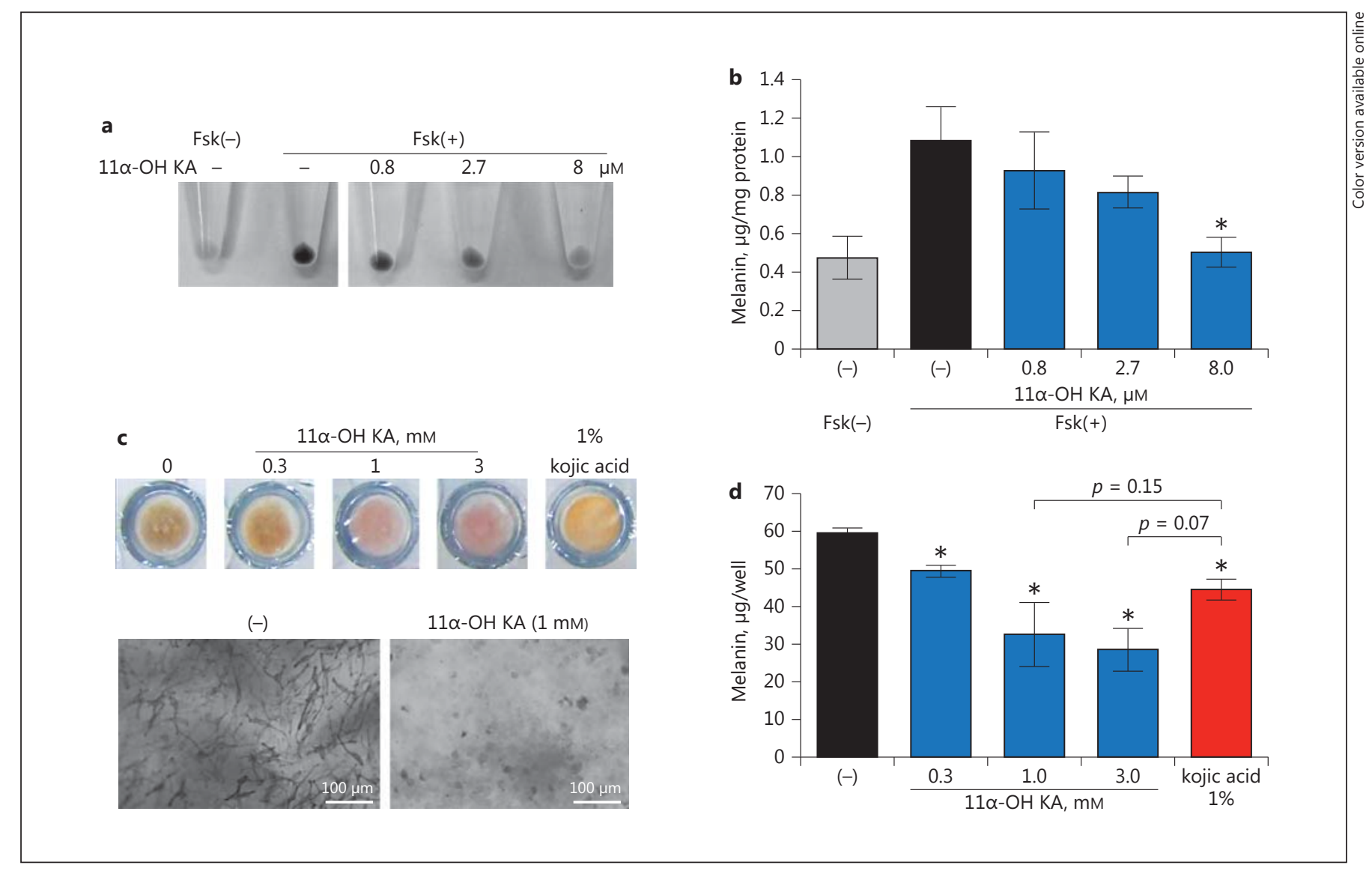

Fig. 2. 11a-OH KA inhibits melanin synthesis in a dose-dependent manner. a B16F10 melanoma cells were treated with Fsk $(20 \mu \mathrm{M})$ for $72 \mathrm{~h}$ together with indicated concentrations of $11 \mathrm{a}-\mathrm{OH} \mathrm{KA}$. b The melanin content was measured after normalization by protein concentration $(n=3$, means and SD are indicated $) * p<0.05$ compared with Fsk only. c $11 \alpha-\mathrm{OH}$ KA or kojic acid dissolved in PBS was added onto the surface of a 3D human skin model com-

MS analyses (Fig. 1e) suggested that these compounds were glycosylated diterpenes. Based on HRESIMS and ${ }^{1} \mathrm{H}-$ NMR data, which had some impurities, Fr. A was deduced to be ent-11a-hydroxy-15-oxokaur-19-oic acid 3-glucoside (11 $\alpha$-OH 16,17-dihydro KA 3-glucoside) [16], whereas Fr. B contained 11a-OH KA 3-glucoside, the enone form of the compound in Fr. A [16]. Only Fr. B was able to inhibit melanogenesis in B16F10 melanoma cells.

Fr. 6 was subjected to hydrolysis to deglycosylate the $11 \alpha-\mathrm{OH}$ KA compound. Then, the deglycosylated kaurens were collected by $\mathrm{C}_{18}$-ODS column chromatography (Fr. $6^{\prime}$; Fig. 1f), and 11a-OH KA was separated using recycling column chromatography, and its structure was confirmed to be $11 \alpha-\mathrm{OH}$ KA by NMR analyses (see Materials and Methods).

11a-Hydroxy-15-oxo-kaur-16-en-19-oic Acid on Inhibition of Melanogenesis posed of human primary melanocytes and multilayer keratinocytes. After 14 days (with medium and test compounds changed every 2 days), incubation of the melanin deposition in the $3 \mathrm{D}$ human skin model was evaluated under a microscope with low (upper image) and high (lower image) magnification. $\mathbf{d}$ Melanin content in the 3D human skin model was measured $(n=3) .{ }^{*} p<0.05$ compared with that with PBS only.

\section{$11 \alpha-O H$ KA Inhibits Melanin Synthesis in a \\ Dose-Dependent Manner}

To elucidate the mode of action of $11 \alpha-\mathrm{OH} \mathrm{KA}, \mathrm{B} 16 \mathrm{~F} 10$ melanoma cells were treated with Fsk for $72 \mathrm{~h}$ along with $11 a-O H$ KA (Fig. 2a). Quantification of the melanin content in B16F10 cells showed that 11a-OH KA inhibited melanin synthesis in a dose-dependent manner (Fig. 2b). A 3D human skin model suggested that, despite weak significance, 1 and $3 \mathrm{~mm} 11 \mathrm{a}-\mathrm{OH}$ KA more efficiently inhibited melanin synthesis than 1\% kojic acid (approximately $70 \mathrm{~mm}$, often included in cosmetic items) (Fig. 2c, d).

\section{$11 \alpha-O H$ KA Suppresses Tyrosinase Expression}

Since Fsk rapidly induces MITF activity, which then promotes expression of melanogenic enzymes, including

Skin Pharmacol Physiol 2017;30:205-215 209 


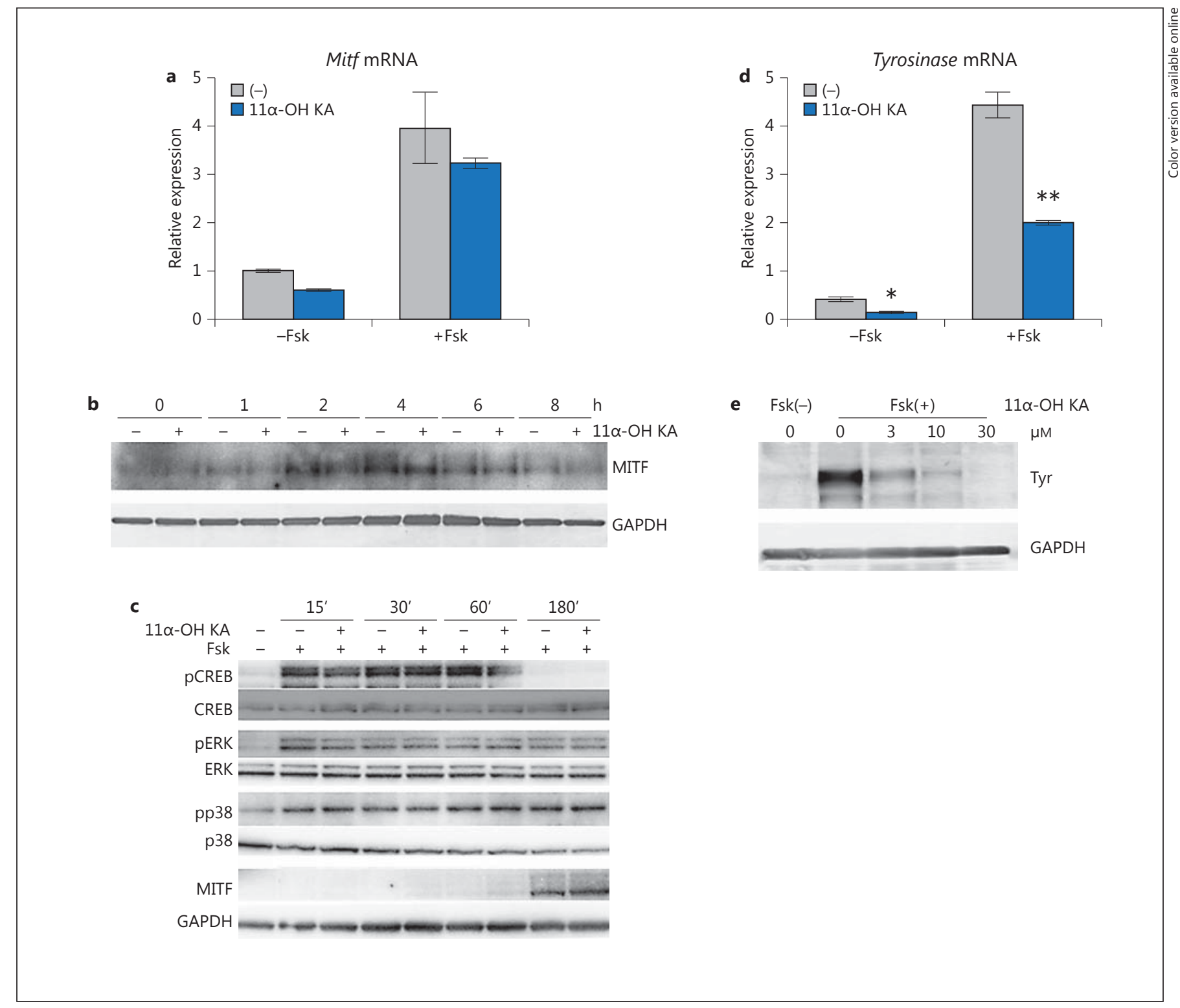

Fig. 3. 11a-OH KA suppresses tyrosinase mRNA and protein levels. a Total RNA was extracted from B16F10 melanoma cells that had been treated with Fsk $(20 \mu \mathrm{M}$ for $3 \mathrm{~h})$ together with $11 \mathrm{a}-\mathrm{OH}$ $\mathrm{KA}(10 \mu \mathrm{M})$ and used as templates for quantitative PCR to measure Mitf mRNA expression levels ( $n=2$, means and SD are indicated). b Western blot analysis of MITF protein expression in B16F10 melanoma cells treated with Fsk $(20 \mu \mathrm{M})$ and $11 \alpha-\mathrm{OH} \mathrm{KA}(10 \mu \mathrm{M})$ for 1-8 h. c Signal status in Fsk- and 11a-OH KA-treated B16F10 cells was examined by Western blot ( $\sim 180 \mathrm{~min})$. d Tyrosinase mRNA levels in B16F10 melanoma cells were measured after treatment for $48 \mathrm{~h}$ with Fsk and 11a-OH KA $(n=2) .{ }^{*} p<0.05,{ }^{* *} p<$ 0.01 compared with that with control $(-)$ (no treatment). e Tyrosinase (Tyr) protein levels were evaluated in cells incubated with Fsk for $48 \mathrm{~h}$ with indicated concentrations of $11 \alpha-\mathrm{OH} \mathrm{KA}$. tyrosinase, we first examined the effects of $11 \alpha-\mathrm{OH} \mathrm{KA}$ on MITF expression in B16F10 melanoma cells. Quantitative PCR (Fig. 3a) and Western blot analyses (Fig. 3b) showed that $11 \alpha-\mathrm{OH}$ KA had no effect on MITF expression despite unexplainable inhibition of Mitf mRNA levels when it is added without Fsk. In addition, activation (phosphorylation) levels of key molecules, such as CREB, ERK, and p38, at the early phase of the Fsk treatment were not changed by $11 \alpha-\mathrm{OH} \mathrm{KA} \mathrm{(Fig.} \mathrm{3c).} \mathrm{On} \mathrm{the} \mathrm{other} \mathrm{hand,}$ both tyrosinase mRNA and protein levels (Fig. 3d, e) were suppressed by $11 \alpha-\mathrm{OH} \mathrm{KA}$, possibly independent of the Fsk treatment (mRNA levels in Fig. 3d). 
a
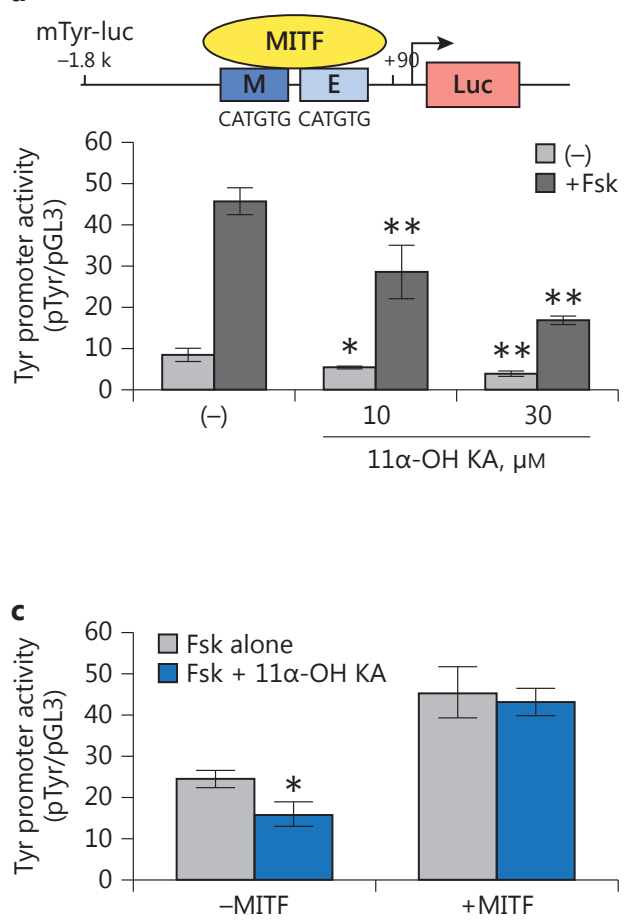

b
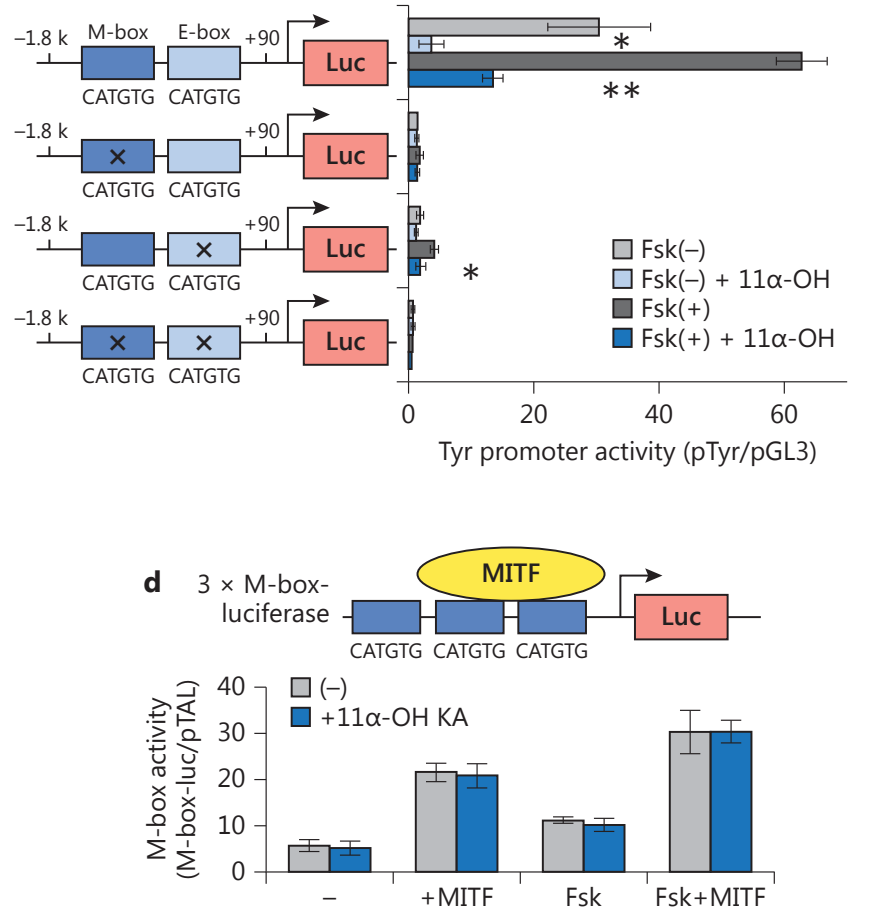

Fig. 4. 11a-OH KA suppresses tyrosinase promoter activities. a pGL3-mouse tyrosinase promoter vector was transformed into B16F10 melanoma cells together with an internal TK reporter. After $24 \mathrm{~h}$, Fsk $(20 \mu \mathrm{M})$ and indicated concentrations of $11 \mathrm{a}-\mathrm{OH} \mathrm{KA}$ were added to the culture medium, and the cells were incubated further for $24 \mathrm{~h}\left(n=4\right.$, means and SD are indicated). ${ }^{*} p<0.05$, ** $p<0.01$ compared with that with the control $(-)$. b The promoter region of the mouse tyrosinase gene was mutated $(n=3$, means and $\mathrm{SD}$ are indicated). ${ }^{*} p<0.05,{ }^{* *} p<0.01$ compared with that with Fsk(-) or Fsk(+). c The expression vector for mouse MITF was cotransformed with the pGL3 mouse tyrosinase promoter vector $\left(n=3\right.$, means and SD are indicated). ${ }^{*} p<0.05$ compared with that with Fsk alone. d The $3 \times$ M-box-luciferase vector was transformed into B16F10 melanoma cells together with/without the MITF-expression vector. After $24 \mathrm{~h}$, Fsk $(20 \mu \mathrm{M})$ was added to the culture medium and the cells were incubated further for $24 \mathrm{~h}$ $(n=3)$.
$11 \alpha-O H$ KA Suppresses Tyrosinase Promoter Activity

To examine whether the reduction of tyrosinase mRNA levels was the result of suppression of promoter activities, we performed a reporter assay using the $-1.8 \mathrm{~kb}$ mouse tyrosinase promoter-luciferase vector (Fig. $4 \mathrm{a}$ ). The tyrosinase promoter activity was inhibited by $11 \alpha-\mathrm{OH} \mathrm{KA}$ in a dose-dependent manner. To rule out the possible contribution of MITF to this suppressed activity, 2 MITF-binding sites (M- and E-box) were disrupted and used in the reporter assay (Fig. 4b). The suppressive effects of $11 a-$ $\mathrm{OH} \mathrm{KA}$ on the tyrosinase promoter were weakened with disruption of the MITF-binding site, particularly with the M-box, and the suppression of 11a-OH KA was completely eliminated with double-site disruption. Given our observations regarding MITF mRNA and protein levels (Fig. 3a, b), overexpression of MITF created further confusion that the overexpressed MITF prevented 11a-OH KA-induced suppression of tyrosinase promoter activity (Fig. 4c).

To verify the role of MITF and the effect of its expression level on 11a-OH KA-mediated suppression of tyrosinase promoter activity, we constructed a $3 \times$ M-boxluciferase vector (Fig. 4d). Neither the basal (without Fsk) nor the stimulated (by Fsk or MITF overexpression) Mbox-derived promoter activities were affected by $11 \alpha-\mathrm{OH}$ KA. These results suggest that $11 \alpha-\mathrm{OH}$ KA-mediated suppression of tyrosinase promoter activity requires MITF. However, 11a-OH KA might not act through 


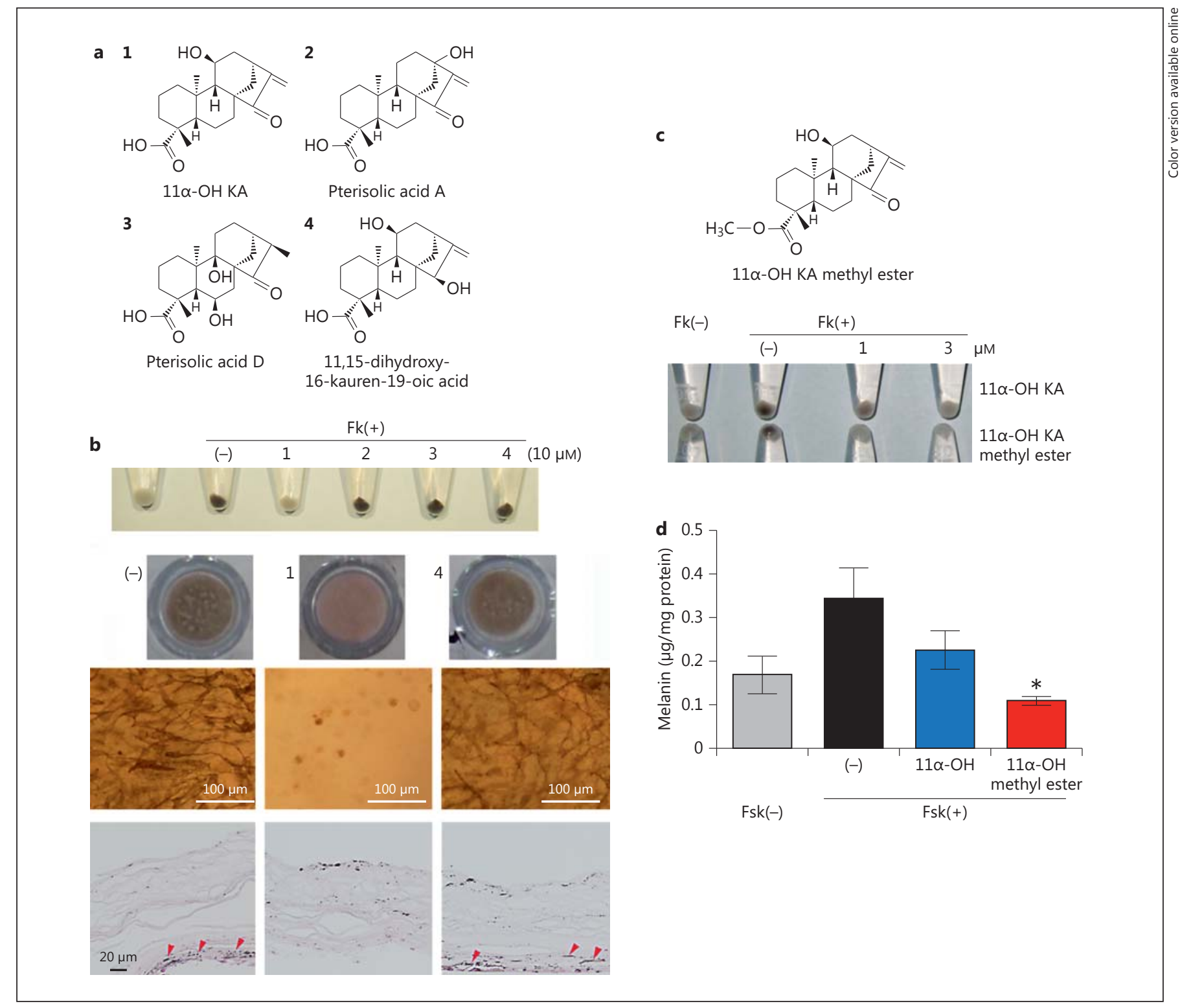

Fig. 5. Structure-activity relationship on melanin-synthesis inhibition. a Structures of $11 \alpha-\mathrm{OH}$ KA and its related compounds. B16F10 melanoma cells were treated with Fsk $(20 \mu \mathrm{M})$ for $48 \mathrm{~h}$ together with the compounds $(10 \mu \mathrm{M})$, and cells were collected into 1.5 - $\mathrm{mL}$ tubes. b 11a-OH KA and dihydroxy KA (compound 4) were examined in 3D human skin models (14 days with $1 \mathrm{mM}$ compounds). Photos taken from the surface (upper image: low magnification) and bottom (middle image: high magnification) of the $3 \mathrm{D}$ human skin mod-

modulation of MITF expression levels or posttranslational activation. One possibility is that $11 \alpha-\mathrm{OH} \mathrm{KA}$ inhibits unknown factors that support MITF recruitment to the tyrosinase promoter. els are shown. Melanin was visualized by Fontana-Masson staining on vertical sections of the 3D human skin models (lower image). Arrowheads indicate melanin-positive cells. c The carboxyl group at the 19 position of $11 \mathrm{a}-\mathrm{OH} \mathrm{KA}$ was converted into methyl ester, and its melanin-synthesis inhibition activity was evaluated in B16F10 melanoma cells ( $20 \mu \mathrm{M}$ Fsk for $48 \mathrm{~h})$. d The melanin content in the B16F10 melanoma cells was measured ( $3 \mu \mathrm{M}$ compounds, 20 $\mu \mathrm{M}$ Fsk; $n=3){ }^{*} p<0.05$ compared with that with Fsk only.

\section{Structure-Activity Relationship of ent-Kaurens on Melanin Synthesis Inhibition}

Finally, we examined the structure-activity relationship of $11 \alpha-\mathrm{OH} \mathrm{KA}$ and its related compounds on the suppressive activities it has: only $11 \alpha-\mathrm{OH}$ KA could sup- 


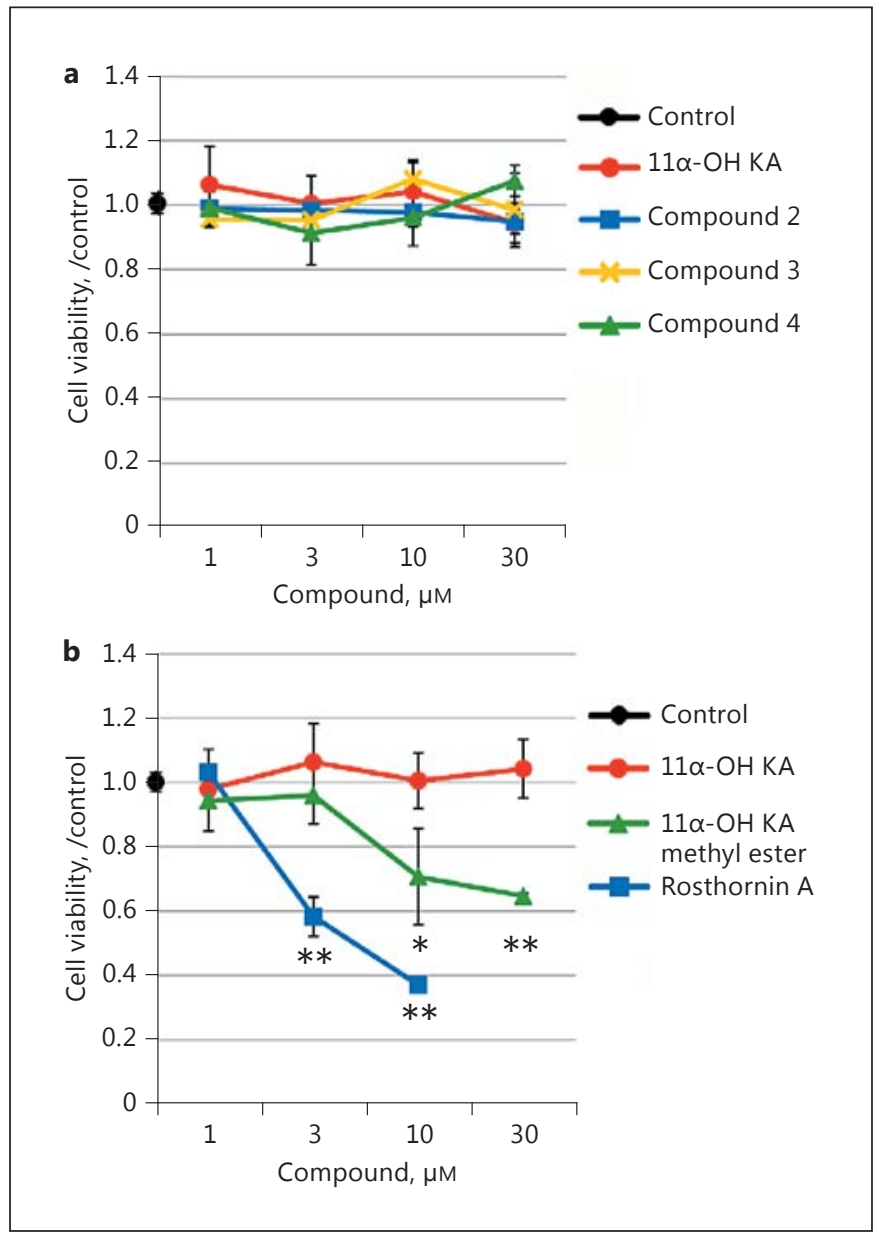

Fig. 6. The COOH group at 19 position of $11 a-O H$ KA reduces cell toxicity. a B16F10 melanoma cells $\left(1 \times 10^{4}\right)$ were incubated with $11 \mathrm{a}-\mathrm{OH} \mathrm{KA}$ and its related compounds (see Fig. 5a) for $24 \mathrm{~h}$. Cell viability was measured by using cell counting kit 8 . Each value at OD450 was normalized by that without compounds (control) $(n=$ 5 , means and SD are indicated). $\mathbf{b}$ The same assay was performed with $11 \mathrm{a}-\mathrm{OH} \mathrm{KA}$, its methyl ester, or rosthornin A (the 19 position is hydroxymethyl) ( $n=5$, means and SD are indicated). ${ }^{*} p<0.05$, ** $p<0.01$ compared with that with the control $(-)$.

press melanogenesis (Fig. 1e, Fig. 5a), whereas the other related compounds examined were not, suggesting that the $\mathrm{OH}$ group at C-11 $\alpha$, carbonyl group at C-15, and double bond at C-16 are essential for suppression of melanogenic activity. The importance of 11a-OH KA was confirmed in 3D human skin models (Fig. 5b). Both unstained images (surface and bottom) and melanin visualization by Fontana-Masson (vertical section) suggested that $11 \alpha-\mathrm{OH} \mathrm{KA}$ decreased the number of melanin-containing cells in the 3D human skin models, especially at the basement side.

11a-Hydroxy-15-oxo-kaur-16-en-19-oic Acid on Inhibition of Melanogenesis
During purification of $11 \alpha-\mathrm{OH} \mathrm{KA}$, we noticed that glycosylation at the $\mathrm{C}-19$ position might not be essential to suppress melanogenesis. To examine the importance of the $\mathrm{C}-19$ position, we modified the $\mathrm{COOH}$ group to methyl ester (Fig. 5c). The methylated compound more efficiently suppressed melanogenesis than did $11 \alpha-\mathrm{OH}$ KA (Fig. 5d), suggesting that $11 \alpha-\mathrm{OH}$ KA methyl ester might be efficiently incorporated into cells, and the $\mathrm{COOH}$ group at $\mathrm{C}-19$ was not essential for the melanogenenic suppressive activity of $11 \mathrm{a}-\mathrm{OH} \mathrm{KA}$.

Finally, we reviewed cell toxicity of $11 \alpha-\mathrm{OH}$ KA. In B16F10 melanoma cells, 11 $\alpha-\mathrm{OH} \mathrm{KA}$ and its related compounds having the $\mathrm{COOH}$ group at their 19 position did not show cell toxic activity up to $30 \mu \mathrm{M}$ (Fig. 6a). In contrast, 11a-OH KA methyl ester showed cell toxicity at $3 \mu \mathrm{M}$. Moreover, rosthornin A that has hydroxymethyl at its 19 position showed high cell toxicity, suggesting that the $\mathrm{COOH}$ group at the 19 position reduced cell toxicity of these kaurens.

\section{Discussion}

Here, we have shown that 11 - $-\mathrm{OH}$ KA from $P$. dispar Kunze leaf extract strongly inhibited melanogenesis in mouse B16F10 melanoma cells and 3D human skin model without obvious cellular toxicity.

Originally found in Pteris semipinnata, 11a-OH KA was shown to inhibit cell proliferation and induce apoptosis in several cell lines $[17,18]$. When human lung cancer A549 cells are treated with $20-80 \mu \mathrm{g} / \mathrm{mL}$ (approximately $60-240 \mu \mathrm{M}$ ) of $11 \alpha-\mathrm{OH} \mathrm{KA}$, the induction of the apoptotic factor p21 and activation of caspase- 3 are observed [17]. In addition, 11a-OH KA induces mitochondrial mediated apoptosis in human nasopharyngeal carcinoma CNE-2Z cells, which is accompanied by a decrease of Bcl-2 and NF- $\kappa \mathrm{B}$ protein levels [18]. However, no other physiologically relevant activity of $11 \alpha-\mathrm{OH} \mathrm{KA}$, including suppression of melanogenesis, had been reported prior to the present report, which is the first study on the effect of $11 \alpha-\mathrm{OH} \mathrm{KA}$ on melanogenesis in mouse and human.

MITF is a key regulator of melanogenic processes and is regulated by a variety of signaling systems at different levels, including gene expression and posttranslational modifications. MITF is phosphorylated by mitogen-activated protein kinase, ribosomal S6 kinase, p38, and GSK3 $\beta$ [19-22]. Phosphorylated MITF can bind to DNA (M-box) more efficiently than its dephosphorylated form. Since $11 \alpha-O H$ KA showed no effect on the MITF expres-

Skin Pharmacol Physiol 2017;30:205-215 213 
sion level or on its activity on the synthetic M-box-derived reporter, the target of $11 \alpha-\mathrm{OH}$ KA might be effectors of MITF present on the tyrosinase promoter. For example, the transcriptional coactivators CBP and p300 are known to interact with the $\mathrm{N}$-terminal transactivation domain of MITF $[23,24]$ and activate MITF-dependent transcription. Similarly, lymphoid enhancer-binding factor 1 binds to the tyrosinase promoter and promotes MITF-dependent tyrosinase gene expression [25, 26].

In this study, 11a-OH KA from $P$. dispar Kunze strongly inhibited melanin production in mouse B16F10 melanoma cells and 3D human skin model. In contrast to the apoptotic activities of $11 \alpha-\mathrm{OH} \mathrm{KA}$ and its related kaurens, this melanogenic inhibitory effect highly depended on the specific chemical structure of this compound, suggesting that the melanogenic targets and signaling cascades modulated by $11 \alpha-\mathrm{OH} \mathrm{KA}$ might be different from those targeted in its cell death signaling activity. Notably, 11a-OH, 15-oxy, and 16-en moieties in the ent-kauren skeleton are essential for melanogenesis suppression, while the $\mathrm{COOH}$ group at the 19 position may contribute to escape from cellular targets that lead to cell death.

In addition to the antimelanogenic activity, we found that $11 \alpha-\mathrm{OH} \mathrm{KA}$ had anti-inflammatory activities, such as suppression of cytokine production, in human keratinocytes damaged by UV. To put 11a-OH KA's beneficial properties into practical use, we first registered "Pteris Dispar Leaf Extract" on the list of International Nomenclature of Cosmetic Ingredients, INCI, and the extract was subjected to human safety studies, including in vitro skin irritation tests using 3D human skin models, genotoxicity tests (Ames tests), in vivo primary skin irritation test (24-hour closed patch test), cumulative skin irritation and skin sensitization test (Repeated Insult Patch Test, RIPT), and in vitro 3T3 Neutral Red Uptake (NRU) phototoxicity test. Fortunately, the extract, up to $1 \%(\mathrm{w} / \mathrm{w})$, has been found to have no toxic properties. Coupling with these safety studies, elucidation of the molecular mechanisms by which $11 \alpha-\mathrm{OH} \mathrm{KA}$ inhibits melanogenesis is also needed.

\section{Acknowledgements}

We thank Mrs. Junko Morita, Ms. Mai Kagawa, Dr. Yumi Itoh (National institute of Biomedical Innovation), Mr. Akihiro Hojo, Ms. Tomoko Onishi, and Ms. Yuko Shimono (Kansai University) for their technical support. This study was partially supported by a project subsidized by the New Energy and Industrial Technology Development Organization (NEDO), and the MEXT-Supported Program for the Strategic Research Foundation at Private Universities (2013-2017).

\section{Statement of Ethics}

Preparation of materials from human souse was undertaken through the application and approval of strict ethical principles of the provider Japan Tissue Engineering Co., Ltd., Aichi, Japan (see http://www.jpte.co.jp/english/business/ethical_policy.html).

\section{Disclosure Statement}

A.K. and M.Y. are employees of Momotani Juntenkan Ltd., which paid 6,900,000 JPY, 2015 FY toward the costs of this study. The other authors declare that they have no conflicts of interest.

\section{References}

1 Boissy RE: Melanosome transfer to and translocation in the keratinocyte. Exp Dermatol 2003; 12:5-12.

2 Gilchrest BA, Park HY, Eller MS, Yaar M: Mechanisms of ultraviolet light-induced pigmentation. Photochem Photobiol 1996;63: $1-10$.

3 Yamada T, Hasegawa S, Inoue Y, Date Y, Arima M, Yagami A, Iwata Y, Takahashi M, Yamamoto N, Mizutani H, Nakata S, Matsunaga $\mathrm{K}$, Akamatsu H: Accelerated differentiation of melanocyte stem cells contributes to the formation of hyperpigmented maculae. Exp Dermatol 2014;23:652-658.
4 d'Ischia M, Wakamatsu K, Napolitano A, Briganti S, Garcia-Borron JC, Kovacs D, Meredith P, Pezzella A, Picardo M, Sarna T, Simon JD, Ito S: Melanins and melanogenesis: methods, standards, protocols. Pigment Cell Melanoma Res 2013;26:616-633.

5 Ando H, Oka M, Ichihashi M, Mishima Y: Protein kinase $\mathrm{C}$ and linoleic acid-induced inhibition of melanogenesis. Pigment Cell Res 1990;3:200-206.

6 Kim DS, Park SH, Kwon SB, Li K, Youn SW, Park KC: (-)-Epigallocatechin-3-gallate and hinokitiol reduce melanin synthesis via decreased MITF production. Arch Pharm Res 2004;27:334-339.

7 Kahn V: Effect of kojic acid on the oxidation of DL-DOPA, norepinephrine, and dopamine by mushroom tyrosinase. Pigment Cell Res 1995;8:234-240.
8 Jimbow K, Obata H, Pathak MA, Fitzpatrick TB: Mechanism of depigmentation by hydroquinone. J Invest Dermatol 1974;62:436-449.

9 Seiji M, Yoshida T, Itakura H, Irimajiri T: Inhibition of melanin formation by sulfhydryl compounds. J Invest Dermatol 1969;52:280286.

10 Ni-Komatsu L, Tong C, Chen G, Brindzei N, Orlow S: Identification of quinolines that inhibit melanogenesis by altering tyrosinase family trafficking. Mol Pharmacol 2008;74: 1576-1586.

11 Lin JY, Fisher DE: Melanocyte biology and skin pigmentation. Nature 2007;445:843850.

12 Vachtenheim J, Borovanský J: “Transcription physiology" of pigment formation in melanocytes: central role of MITF. Exp Dermatol 2010;19:617-627. 
13 Horike N, Kumagai A, Shimono Y, Onishi T, Itoh Y, Sasaki T, Kitagawa K, Hatano O, Takagi H, Susumu T, Teraoka H, Kusano K, Nagaoka Y, Kawahara H, Takemori H: Downregulation of SIK2 expression promotes the melanogenic program in mice. Pigment Cell Melanoma Res 2010;23:809-819.

14 Yamahara M, Sugimura K, Kumagai A, Fuchino $\mathrm{H}$, Kuroi A, Kagawa $\mathrm{M}$, Itoh $\mathrm{Y}$, Kawahara H, Nagaoka Y, Iida O, Kawahara N, Takemori H, Watanabe H: Callicarpa longissima extract, carnosol-rich, potently inhibits melanogenesis in B16F10 melanoma cells. J Nat Med 2016;70:28-35.

15 Bouktaib M, Lebrun S, Atmani A, Rolando C: Hemisynthesis of all the $\mathrm{O}$-monomethylated analogues of quercetin including the major metabolites, through selective protection of phenolic functions. Tetrahedron 2002;58: 10001-10009.

16 Tanaka N, Hata M, Murakami T, Saiki Y, Chen C-M: Weitere Inhaltsstoffe von Pteris dispar Kunze. Chem Pharm Bull 1976;24: 1965-1966.

17 Wu K, Liu Y, Lv Y, Cui L, Li W, Chen J, Liang NC, Li L: Ent-11a-hydroxy-15-oxo-kaur16-en-19-oic-acid induces apoptosis and cell cycle arrest in CNE-2Z nasopharyngeal carcinoma cells. Oncol Rep 2013;29:21012108.
18 Li L, Chen GG, Lu YN, Liu Y, Wu KF, Gong XL, Gou ZP, Li MY, Liang NC: Ent-11ahydroxy-15-oxo-kaur-16-en-19-oic-acid inhibits growth of human lung cancer A549 cells by arresting cell cycle and triggering apoptosis. Chin J Cancer Res 2012;24:109115.

19 Weilbaecher KN, Motyckova G, Huber WE, Takemoto CM, Hemesath TJ, Xu Y, Hershey CL, Dowland NR, Wells AG, Fisher DE: Linkage of M-CSF signaling to Mitf, TFE3, and the osteoclast defect in Mitf ${ }^{m i / m i}$ mice. Mol Cell 2001;8:749-758.

$20 \mathrm{Wu}$ M, Hemesath TJ, Takemoto CM, Horstmann MA, Wells AG, Price ER, Fisher DZ, Fisher DE: c-Kit triggers dual phosphorylations, which couple activation and degradation of the essential melanocyte factor Mi. Genes Dev 2000;14:301-312.

21 Takeda K, Takemoto C, Kobayashi I, Watanabe A, Nobukuni Y, Fisher DE, Tachibana M: Ser298 of MITF, a mutation site in Waardenburg syndrome type 2 , is a phosphorylation site with functional significance. Hum Mol Genet 2000;9:125-132.
22 Mansky KC, Sankar U, Han J, Ostrowski MC: Microphthalmia transcription factor is a target of the p38 MAPK pathway in response to receptor activator of NF- $\mathrm{KB}$ ligand signaling. J Biol Chem 2002;277:11077-11083.

23 Sato S, Roberts K, Gambino G, Cook A, Kouzarides T, Goding CR: CBP/p300 as a co-factor for the Microphthalmia transcription factor. Oncogene 1997;14:3083-3092.

24 Price ER, Horstmann MA, Wells AG, Weilbaecher KN, Takemoto CM, Landis MW, Fisher DE: $\alpha$-Melanocyte-stimulating hormone signaling regulates expression of $\mathrm{mi}$ crophthalmia, a gene deficient in Waardenburg syndrome. J Biol Chem 1998;273:3304233047.

25 Wang X, Liu Y, Chen H, Mei L, He C, Jiang L, Niu Z, Sun J, Luo H, Li J, Feng Y: LEF-1 regulates tyrosinase gene transcription in vitro. PLoS One 2015;10:e0143142.

26 Saito H, Yasumoto K, Takeda K, Takahashi K, Fukuzaki A, Orikasa S, Shibahara S: Melanocyte-specific microphthalmia-associated transcription factor isoform activates its own gene promoter through physical interaction with lymphoid-enhancing factor 1 . J Biol Chem 2002;277:28787-28794.
11a-Hydroxy-15-oxo-kaur-16-en-19-oic Acid on Inhibition of Melanogenesis
Skin Pharmacol Physiol 2017;30:205-215 DOI: $10.1159 / 000475471$ 